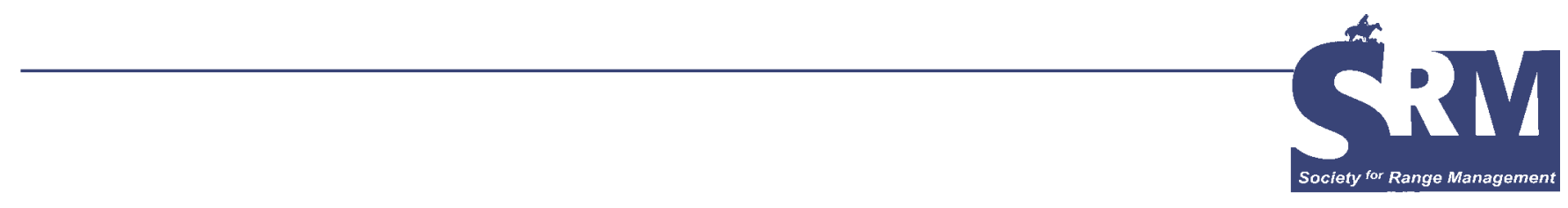

\title{
Is Rangeland Health Relevant to Mongolia?
}

\section{By Bolormaa Damdinsuren, Jeffrey E. Herrick, David A. Pyke, Brandon T. Bestelmeyer, and Kris M. Havstad}

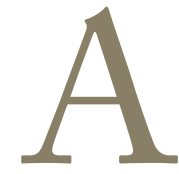

pproximately 800,000 of Mongolia's 2.5 million people depend directly on livestock production and rangelands for their livelihood. Overgrazing is widespread in the western provinces and near the capital city of Ulaanbaatar, but forage is often underutilized in eastern parts of the country. Many important elements of an infrastructure needed to support livestock production systems, including supplemental feeds, spring grazing pastures, and veterinary services, are lacking, and further compound pressures on forage resources. There is an increasing awareness of the importance of healthy rangelands in protecting the country's natural resource base; however, most of the population continues to view rangelands primarily as a food source for livestock.

The rangeland health concept was developed in response to concerns that existing rangeland inventory, assessment, and monitoring protocols were inadequate. ${ }^{1,2}$ This concept is based on the assumption that the sustainability of all environmental services, including livestock forage production, depends on limiting soil erosion and degradation; effectively capturing, storing and releasing water; and on maintaining productive, resilient biological communities (Fig. 1). However, rangeland health does not directly address forage production, or any other environmental service. Consequently, it is possible for land to be described as "healthy" while producing less forage than it could. Consequently, it is not clear that rangeland health is relevant to countries, such as Mongolia, that depend on short-term, as well as long-term, forage production.

To be relevant to Mongolian herders and policymakers, rangeland health must be integrated into a management framework that explicitly includes maximizing long-term forage production as a primary objective. In this article, we 1) briefly review the current status of Mongolian rangelands, 2) discuss the relationship between rangeland health and sustainability, and 3) propose a management framework that uses existing rangeland evaluation protocols to identify early-warning signs of degradation. We believe that the issues associated with adapting the rangeland health concept with other rangeland evaluation and assessment tools for Mongolia are common to many parts of the world, including the United States.

\section{Land Rich and Cash Poor}

Mongolia is the least-densely populated country in the world, with just two people per square kilometer, or an average of approximately 125 acres per person. ${ }^{3}$ Even Australia and Canada (3 people $\cdot \mathrm{km}^{-2}$ ) are more crowded. The United States by comparison has six times more people per area of land (12 people $\left.\cdot \mathrm{km}^{-2}\right)$ than Mongolia. In contrast, Mongolia's economy is one of the smallest, with a per capita gross national product (GNP) of less than US $\$ 500$. The US economy generates over 70 times more per person (US\$35,400). ${ }^{3}$ These figures help explain why Mongolia depends on rangelands to support its growing population (average 2.4\% growth from 1980 to 2000 vs. $1.6 \%$ globally). ${ }^{4}$

\section{Current Status of Mongolian Rangelands}

Mongolian rangelands are primarily grass-dominated and arid to semiarid. Annual precipitation ranges from less than $50 \mathrm{~mm}$ in the south to over $400 \mathrm{~mm}$ at upper elevations in the north. ${ }^{5}$ This gradient generates correspondingly large differences in plant production. Although there appear to 

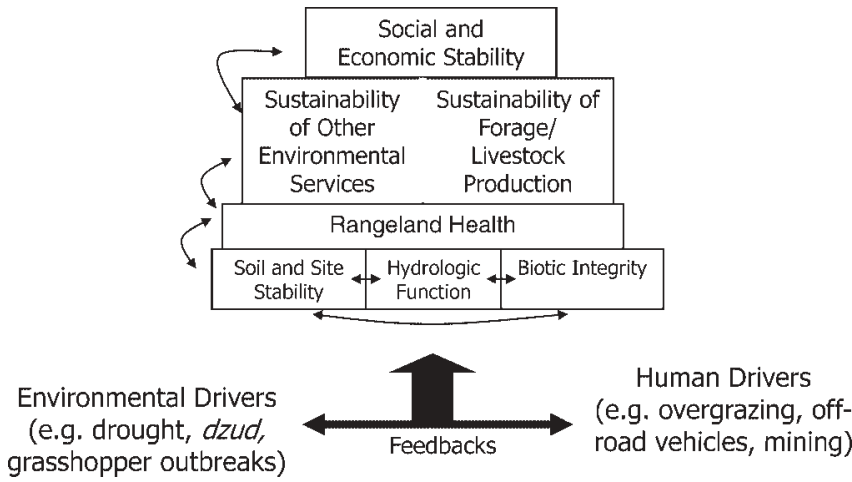

Figure 1. Social and economic stability in Mongolia depends on livestock production, which depends on rangeland health. All three are threatened by interactions between land degradation, extreme weather events (including drought and dzud), and management responses. Rangeland health is the degree to which the integrity of the soil, vegetation, water, and air, as well as ecological processes, are sustained. Arrows indicate feedbacks among the different elements. Dzud is defined as extreme winter weather event, often resulting in high livestock mortality.

have been significant shifts from cool- to warm-season grass dominance in some regions, ${ }^{6}$ most areas do not appear to have experienced the dramatic plant community changes observed in other arid and semiarid rangelands of the world.

\section{Causes of Degradation}

Concern about the status of Mongolia's rangelands has increased due to dramatic increases in livestock populations during the past $15 \mathrm{yr}^{7}$ The primary cause of degradation is overgrazing. Between 1990 and 2000, the number of domestic animals increased 38\%. At least one study also suggests that there has been an overall decline in net primary productivity ${ }^{8}$ and there are increasing signs of localized degradation, including both plant community changes and increased soil erosion (Figs. 2-5). The increased stocking rates are related to changes associated with the conversion from a socialist to a market-based economy that began in 1990. One important change with this conversion was the privatization of livestock ownership. However, land ownership has remained with the government, and this further limits incentives and interest in land management practices. Livestock distribution has also changed with the abandonment of collective grazing systems and increased migration to the capital city, Ulaanbaatar. Consequently, stocking rates have increased by 1.5-3 times near water and urban areas, but densities have remained stable or even declined in more remote areas. ${ }^{9}$

Mongolian herders, like their counterparts in the rest of the world, cite overgrazing associated with drought as the primary cause of land degradation. Periods of below-average precipitation result in significant declines in forage production, which leads to overgrazing unless stocking rates are reduced or supplemental feed is provided. The lack of

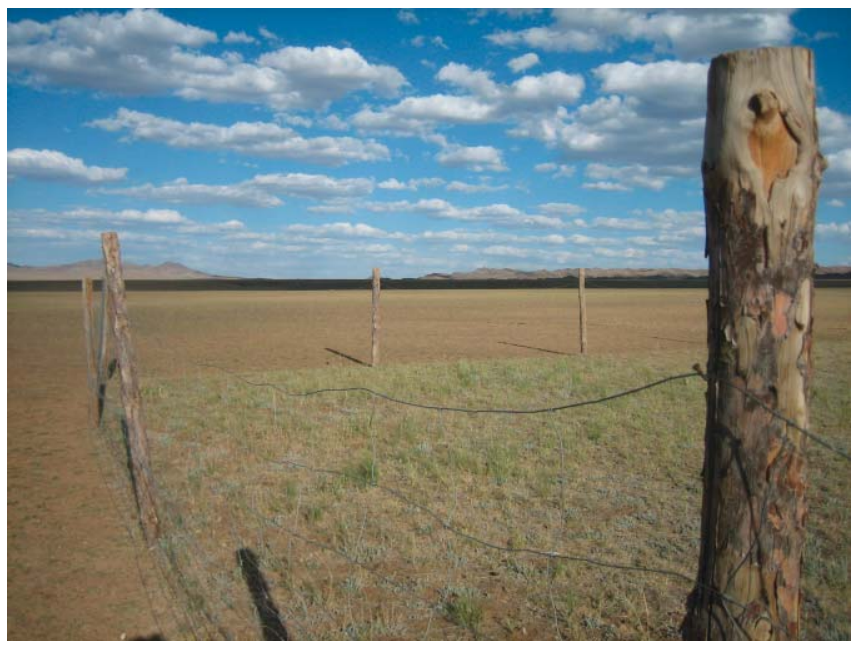

Figure 2. Exclosure supporting recovery of a crested wheatgrass (Agropyron cristatum) in central Mongolia (lat $43^{\circ} 47^{\prime} 43.1^{\prime \prime} \mathrm{N}$, long $\left.103^{\circ} 12^{\prime} 3.6^{\prime \prime} \mathrm{E}\right)$.

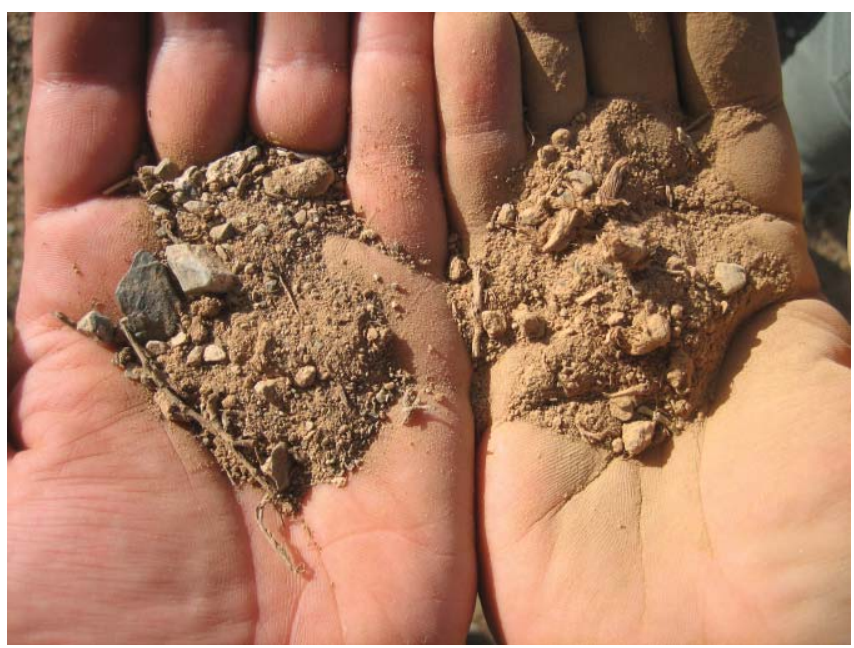

Figure 3. Organic matter recovery is reflected in the darker color of the soil (left) from the exclosure shown in Figure 2.

supplemental forage, and underdeveloped banking, marketing, and transportation infrastructure make it difficult to either limit grazing during early forage growth periods or reduce stocking rates during drought, even if these are herder goals. For example, there is simply no way for the local market to absorb the large amount of meat that would be generated by massive destocking, or to effectively move those animals to export markets where demand is high. This devastating interaction of drought and overstocking, which has been repeatedly demonstrated on all continents in the past century, is perhaps the greatest threat to the sustainability of Mongolia's rangelands. The problem is unfortunately illustrated by the massive livestock losses (estimated at nearly 10 million head) that occurred following drought coupled with severe winter weather in 1999 and 2002.

With these problems come additional and new concerns. Off-road vehicle traffic and mining are now recognized as a 


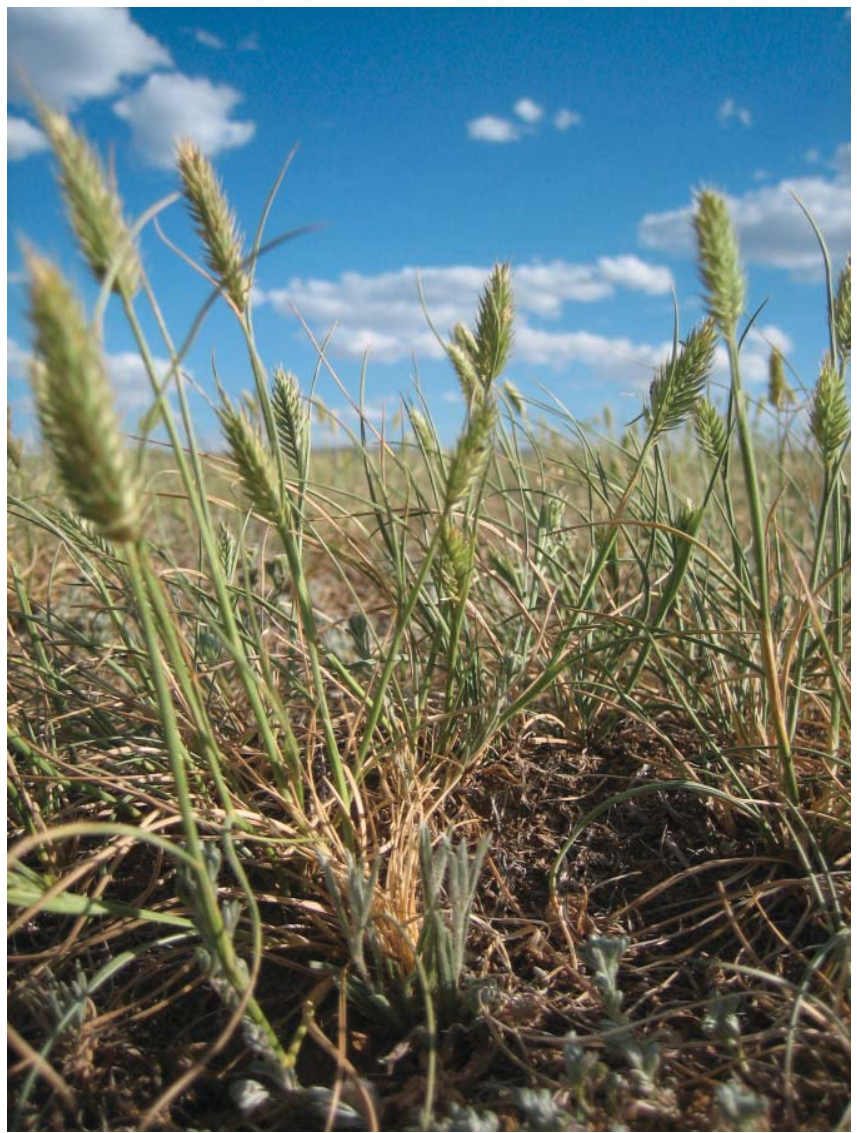

Figure 4. Crested wheatgrass in the exclosure shown in Figure 2.

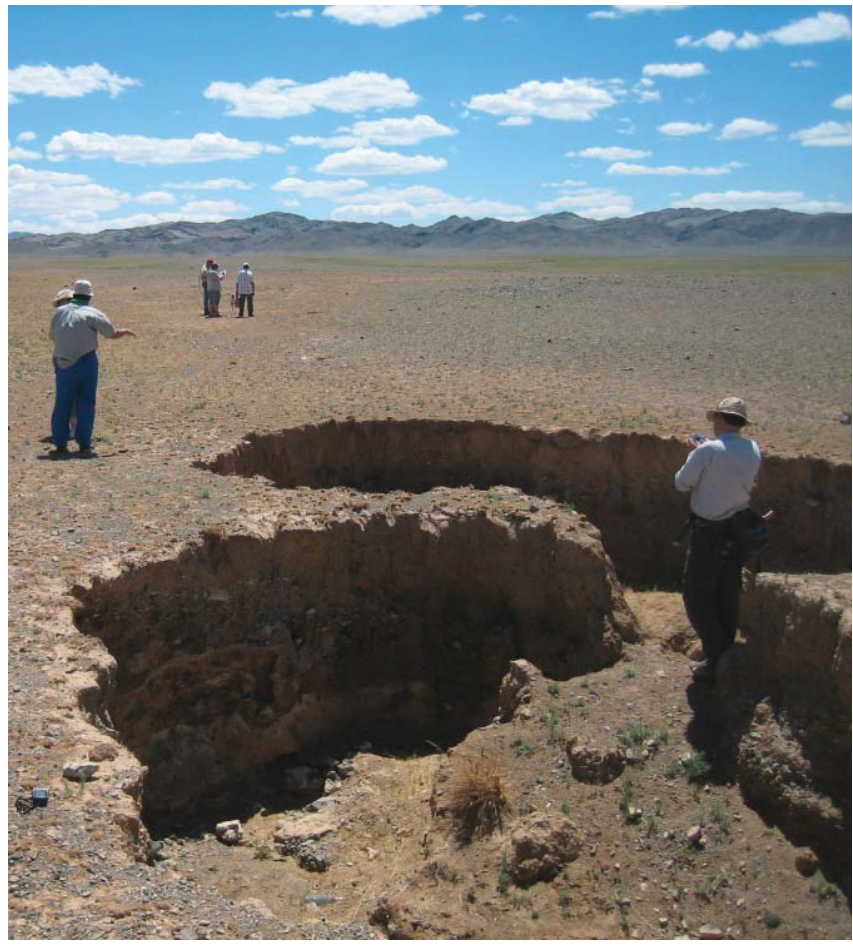

Figure 5. Gully headcut resulting from increased runoff (lat $43^{\circ} 56^{\prime} 05.5^{\prime \prime} \mathrm{N}$, long $\left.103^{\circ} 24^{\prime} 23.1^{\prime \prime} \mathrm{E}\right)$. rapidly increasing source of land degradation. There are few roads in Mongolia and even fewer that are surfaced. As the number of vehicles increases in association with local economic activity including mining, tourism, and other rural development efforts, the number of miles driven both on- and off-road increases. Vehicles are more likely to leave unimproved roads when the soil is wet and most susceptible to compaction. This creates ever-widening sets of parallel tracks of compacted soil.

\section{Management Framework}

Because at least half of Mongolia's population depends directly or indirectly on livestock production, ${ }^{10}$ long-term social and economic stability are tightly linked to rangeland health (Fig. 1). Consequently, the balance between shortterm profits and long-term sustainability of rangelands is arguably more important for the future of Mongolia than it is for most other countries.

The management framework in Figure 6 shows how rangeland health assessments and monitoring might be applied in developing countries such as Mongolia, where optimizing long-term forage production is the primary management objective. The first step of the process is an assessment of rangeland health using the "Interpreting Indicators of Rangeland Health" (IIRH) protocol. ${ }^{11,12}$ IIRH uses 17 indicators to assess the status of three attributes: soil and site stability, hydrologic function, and biotic integrity. Each of the indicators is rated using a reference sheet that describes the expected status of the indicator when the site is at its ecological potential. Because indicators reflect the ecological functioning of the land rather than the presence of a particular plant community, it is often possible for many different plant communities to sustain the potential of the land to support diverse ecosystem services in the future.

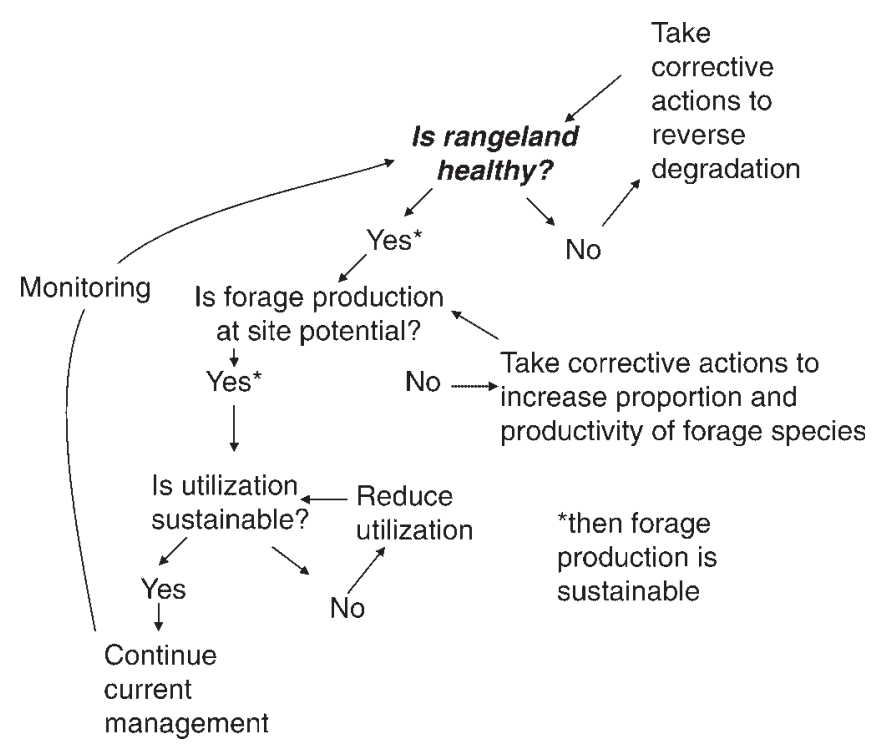

Figure 6. Proposed integration of rangeland health evaluation with existing forage production evaluations and management in Mongolia. 
These communities generally occur in a single ecological "state" in the conceptual state-and-transition models that are increasingly used in the United States to describe rangeland dynamics. ${ }^{13,14} \mathrm{~A}$ unique reference sheet is developed for functionally similar groups of soils in a single climatic zone based on the ecological site concept. ${ }^{15}$ Although Mongolia does not currently have an ecological site classification system, the concept still can be applied to ensure that the appropriate reference is being used.

The second step of the process involves assessing forage productivity relative to its potential for the particular soil and climate (Fig. 6). Mongolia already has an established pasture assessment system in which forage plant cover and composition are considered main indicators. Because there is no organized system to determine soil stability, ecological processes cannot be evaluated as a whole using this system. Therefore, rangeland assessment methodology of Mongolia has to be expanded to address ecological sustainability. ${ }^{16} \mathrm{We}$ recommend that the two assessments, pasture assessment and IIRH, be completed together. Corrective actions are triggered when either assessment indicates that the area is not functioning at its potential.

The third step involves an assessment of the sustainability of current use. These assessments are also commonly conducted in Mongolia. They might be enhanced in the future with the integration of some of the rangeland health indicators. For example, most utilization measures are based on individual plant measurements. However, on highly wind-erodible soils, the most important indicator for soil conservation is the spacing between plants. In these areas, monitoring the size of the gaps created by grazing might be as important as monitoring the amount of forage removed, or cover remaining. ${ }^{17}$

Long-term monitoring is the fourth step. This is particularly critical because both land use and climate are dynamic, and because our understanding of sustainable use levels is imperfect.

\section{Identifying the Degradation Cause}

Rangeland health assessment protocols cannot be used alone to identify the cause of degradation. However, a knowledge of the types of degradation that are occurring (e.g., reduced forage productivity in areas showing linear patterns of soil compaction) together with information on changes in human and environmental drivers (e.g., increased off-road vehicle traffic) can be used to identify probable cause-effect relationships. In this case, the rangeland health assessment shows reduced hydrologic function. The relationships between soil compaction, hydrologic function, and forage productivity are established in the literature. ${ }^{18}$ Other studies have clearly documented the relationship between vehicle traffic and soil compaction. ${ }^{19}$ Together, the evidence suggests that reducing off-road vehicle traffic in the area should at least reduce future degradation. Recovery depends on the presence or restoration of conditions necessary for seedling establishment and plant growth, including seed reserves and soil moisture for establishment and recovery. Removal of the stress alone might not be sufficient, whether the stress is overgrazing or vehicle traffic.

\section{Future Challenges}

These preliminary attempts to adapt and apply the rangeland health concept, and specifically the IIRH protocol to Mongolia, suggest that additional work is needed in three areas: 1) developing more explicit links between the rangeland health attributes and specific land uses and values, including forage production; 2) anticipating new threats, such as invasive species, which could influence rangeland sustainability; and 3) increasing our understanding of how resilience varies throughout the country. ${ }^{20}$ All three of these areas will need to be understood within the context of climate change and its subsequent influences on rangeland productivity.

\section{Conclusions}

We believe that the rangeland health concept can be used to help increase both short-term productivity and long-term sustainability of Mongolian rangelands. Rangeland health assessments have the potential to help Mongolia focus its limited management and monitoring resources on areas that are being degraded. The assessments can help managers focus on recognizing factors that could lead to long-term degradation. Combining assessments of rangeland health, current forage production, and utilization gives managers a tool that allows them to adapt their management to meet changing needs. Long-term monitoring data can then be used to evaluate whether improvements in Mongolian rangelands occur in the future.

\section{Acknowledgments}

We appreciate and are grateful for many conversations with participants in the Green Gold Project and various government and nongovernment organization efforts in Mongolia. This work was supported by a National Science Foundation award to the LTER program at the Jornada Basin at New Mexico State University (DEB 0618210), the US Department of Agriculture Agricultural Research Service program based at the Jornada Experimental Range, and by the Swiss Development Corporation's Green Gold project in Mongolia. The authors recognize that our understanding of these issues is rapidly evolving. The views expressed here are based on our diverse, collective understanding at the time the article was drafted. Finally, we thank Ericha Courtright for editorial assistance.

\section{References}

1. National Research Council. 1994. Rangeland health: new methods to classify, inventory, and monitor rangelands. Washington, DC, USA: National Academy Press. 200 p.

2. Society for Range Management Task Group on Unity in Concepts and Terminology. 1995. New concepts for 
assessment of rangeland condition. Journal of Range Management 48:271-282.

3. World Bank. 2004. World Development Indicators. Washington, DC, USA: World Bank Publications. 420 p.

4. World Resources Institute. 2003. Earthtrends: the environmental information portal. Available at: http://Earthtrends. wri.org. Accessed 2 February 2006.

5. Рнотіus.сом. 2005. Based on USSR Council of Ministers, 1975, Mongolskaia Narodnaia Respublika, spravochnaia karta (Mongolian People's Republic, Reference Map). Moscow, Russia: Main Administration of Geodesy and Cartography. Available at: http://www.photius.com/countries/mongolia/ climate/mongolia_climate_climate.html. Accessed 25 October 2005.

6. Chuluun, T., L. L. Tieszen, and D. Ojima. 1999. Land use impact on $\mathrm{C}_{4}$ plant cover of temperate East Asian grasslands. In: K. Otsubo [ED.]. NIES Workshop on Information Bases and Modeling for Land-use and Land-cover Changes Studies in East Asia. Center for Global Environmental Research. p. 103-109.

7. Mongolian Statistics. 2005. Mongolian statistics book. Ulaanbaatar, Mongolia: Ulaanbaatar Press. 375 p.

8. Hicke, J. A., and D. S. Ojima. 2003. Changes in Mongolia vegetation productivity (1982-1998) derived from satellite observations. Proceedings of the American Geophysical Union, Fall Meeting 2003 (abstract \#B51E-1018).

9. Tserendash, S. 2003. Rangeland, land, livestock [in Mongolian]. Ulaanbaatar, Mongolia: Ulaanbaatar Press. 270 p.

10. Fernandez-Gimenez, M. E. 2000. The role of Mongolian nomadic pastoralists' ecological knowledge in rangeland management. Ecological Applications 10:1318-1326.

11. Pyke, D. A., J. E. Herrick, P. Shaver, and M. Pellant. 2002. Rangeland health attributes and indicators for qualitative assessment. Journal of Range Management 55:584-597.

12. Pellant, M., P. Shaver, D. A. Pyke, and J. E. Herrick. 2005. Interpreting indicators of rangeland health, version 4. Technical Reference 1734-6. Denver, CO, USA: US Department of the Interior, Bureau of Land Management, National Science and Technology Center. $122 \mathrm{p}$.

13. Bestelmeyet, B. B., J. R. Brown, K. M. Havstad, R. Alexander, G. Chavez, and J. Herrick. 2003. Development and use of state-and-transition models for rangelands. Journal of Range Management 56:114-126.
14. Stringham, T. K., W. C. Krueger, and P. L. Shaver. 2003. State and transition modeling: an ecological process approach. Journal of Range Management 56:106-113.

15. Herrick, J. E., B. T. Bestelmeyer, S. Archer, A. Tugel, And J. R. Brown. 2006. An integrated framework for sciencebased arid land management. Journal of Arid Environments 65:319-335.

16. BolormaA, D. 2005. Extend new methodology for assessment of rangeland health and quality. Abstract 12-412. Proceedings of the trend for agricultural sector Mongolia; Ulaan-baatar, Mongolia.

17. Herrick, J. E., J. W. Van Zee, K. M. Havstad, L. M. Burkett, and W. G. Whitford. 2005. Monitoring manual for grassland, shrubland and savanna ecosystems. Las Cruces, NM, USA: USDA-ARS Jornada Experimental Range. Distributed by University of Arizona Press, Tucson, AZ, USA. $236 \mathrm{p}$.

18. Thurow, T. L. 1991. Hydrology and erosion. In: R. Heitschmidt and J. Stuth [EDs.]. Grazing management: an ecological perspective. Portland, OR, USA: Timberline Press. p. $141-159$.

19. Webb, R. H., And H. G. Wilshire [eds]. 1983. Environmental effects of off-road vehicles: impacts and management in arid regions. New York, NY, USA: Springer-Verlag. 534 p.

20. Bestelmeyer, B., K. Havstad, B. Damindsuren, G. Han, J. R. Brown, J. Herrick, C. Steele, and D. Peters. In Press. Resilience theory in models of rangeland ecology and restoration: the evolution and application of a paradigm. In: R. J. Hobbs and K. Suding [EDs.]. New models for ecosystem dynamics and restoration. Washington, DC, USA: Island Press.

Authors are Biologist, Research Institute of Animal Husbandry, Zaisan 53, Ulaanbaatar 210153, Mongolia (Damdinsuren); Research Soil Scientist, jherrick@nmsu.edu (Herrick), Research Ecologist (Bestelmeyer), and Supervisory Scientist (Havstad), USDA-ARS Jornada Experimental Range, PO Box 30003, MSC 3JER, Nerw Mexico State University, Las Cruces, NM 88003, USA; and Research Rangeland Ecologist, US Geological Survey, Forest E Rangeland Ecosystem Science Center, 3200 SW Jefferson Way, Corvallis, OR 97331, USA (Pyke). 